\title{
Stress-Strain Model of Concrete Damaged by Freezing and Thawing Cycles
}

\author{
Muttaqin Hasan ${ }^{1}$, Hidetoshi Okuyama ${ }^{2}$, Yasuhiko Sato ${ }^{3}$ and Tamon Ueda ${ }^{4}$
}

Received 20 January 2003, accepted 2 July 2003

\begin{abstract}
This study investigates the dependence of the mechanical behavior of concrete, such as strength, stiffness, and deformation capacity on the damage caused by freezing and thawing cycles (FTC). A stress-strain model for concrete damaged by freezing and thawing prior to the application of mechanical loading was proposed based on plasticity and fracture of concrete elements. The FTC fracture parameter was introduced to explain the degradation in initial stiffness of concrete resulting from freezing and thawing damage. Based on experimental data, the FTC fracture parameter was empirically formulated as a function of plastic tensile strain caused by freezing and thawing with the assumption that the plastic strain was caused by the combined effects of FTC and mechanical loading damage. The stress-strain relationships obtained by the proposed model were compared with the experimental data.
\end{abstract}

\section{Introduction}

Concrete as a porous media has the ability to absorb and retain moisture. This characteristic makes unprotected concrete structures susceptible to frost damage. When the temperature drops below $0^{\circ} \mathrm{C}$, ice formation is initiated at the surface of the concrete through ice nucleating germs such as ice crystals, snow flakes, white frost, dust or aerosol particles or unevern parts of the surface (Kaufmann, 2002). Powers (1953 cited by Kaufmann 2002) stated that once ice formation is initiated, the pore solution will freeze at the freezing point, disturbing thermodynamic equilibrium and initiating hydraulic pressure. Kaufmann (2002) stated that due to the lower chemical potential, unfrozen pore solution mostly in smaller pores flows toward the existing ice in larger pores and freezes there. This water redistribution induces internal shrinkage and additional hydrostatic pressure. The experimental results demonstrated that this water redistribution is the prerequisite for damage formation during the ongoing and subsequent frost cycles. Penttala and Al-Neshawy (1999) reported that if the pore system is not filled with sufficient water in which hydraulic pressures are induced into the material, then the first freezing of the pore water forms an under-pressure (negative hydraulic pressure) into the pore system, and the concrete contracts as a result. The con-

\footnotetext{
${ }^{1}$ Post Doctoral Researcher, Division of Structural and Geotechnical Engineering, Hokkaido University, Japan. E-mail: muttaqin@eng.hokudai.ac.jp

${ }^{2}$ Engineer, Hokkaido Electric Power, Co. Ltd.

${ }^{3}$ Research Associate, Division of Structural and Geo-technical Engineering, Hokkaido University, Japan.

${ }^{4}$ Associate Professor, Division of Structural and Geo-technical Engineering, Hokkaido University, Japan.
}

traction of concrete during first freezing was also experimentally investigated (Penttala 2002; Penttala and Al-Neshawy, 2002). Having a higher thermal expansion than concrete, the ice contracts more at the lowest temperatures, creating empty pore space (Penttala and Al-Neshawy, 2002). This empty pore space is then refilled with water from the smaller pores that are connected to the newly created pore space, and the water freezes there. Kaufmann (2002) also reported that during thawing, the ice in the new pore space expands more than the surrounding concrete, thereby increasing tension in the concrete. Also when the temperature rises above $0^{\circ} \mathrm{C}$, the additional pore space due to deterioration (crack, etc.) is refilled with water from outside and the degree of saturation increases (Kaufmann 2002; Kasparek and Setzer 2002). The moisture content in the pore structures contributes significantly in the damage of concrete under frost action (Fagerlund 2002).

The irreversible tensile deformation and cracking during freezing and thawing cycles (FTC) affect the mechanical properties of concrete, namely the strength, stiffness, and deformation capacity of concrete (Panchenko 1997; Hasan et al. 2001). Ideally the changes in the material properties resulting from FTC damage should therefore be considered in the stress analysis of reinforced concrete structures that have been affected by FTC. As a result, development of pertinent constitutive models that recognize the effect of FTC damage is necessary. For this purpose, Hasan et al. (2002) proposed a stress-strain model for concrete affected by FTC prior to the application of a compression load. The proposed model was based on the elasto-plastic and fracture model for concrete subjected to mechanical loading (Maekawa and Okamura 1983). However the model does not consider the effects of irreversible tensile deformation and fracture of elements during FTC. It also requires the measured compressive 
strength for damaged concrete for the computation of the stress-strain relationship. In this study the model has been modified to take into account the effects of irreversible tensile deformation and eliminate the need for measured compressive strength. The modified model introduces the fracture parameter under the effect of FTC in addition to the fracture parameter under the effect of mechanical load. It is designed for both simple calculation of sectional member strength and finite element analysis.

Concrete in real structures is subjected to the combined actions of FTC and mechanical loadings. In a first stage, development of a model for the simplified condition in which the concrete is first subjected to FTC and then mechanical loading was considered. This was because most of the concrete in real structures is subjected to rather small tensile and compressive stresses in comparison with its tensile and compressive strengths. A model for more general cases of combined actions will be studied in the second stage.

\section{Previous model}

In the elasto-plastic and fracture model, Maekawa and Okamura (1983) assumed that concrete is constructed of a group of constituent elements that are arranged in parallel as shown in Fig. 1(a). Under the effects of mechanical loading, the following phenomena were considered to happen. The collapse of fine voids of concrete and slip between coarse aggregate and mortar during application of the compression load result in the plasticity of concrete. The unloading-reloading stiffness is not constant because of accumulated mechanical damage such as the appearance of microcracking, microscopic buckling and collapse of mortar and aggregate. This

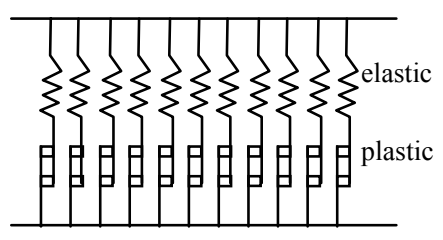

(a)

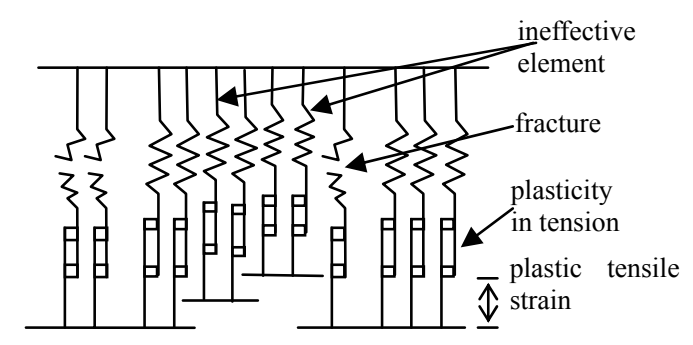

(b)

Fig. 1 Constituent elements; (a) Group of constituent elements; (b) Fracture and plasticity of some constituent elements during FTC.

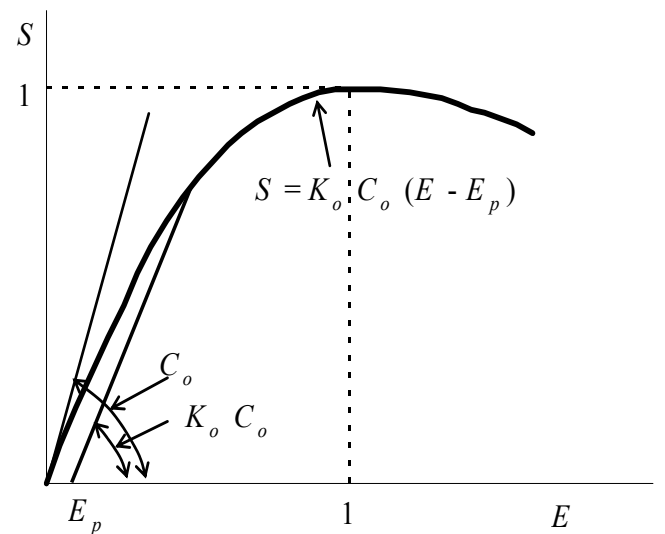

Fig. 2 Equivalent stress-equivalent strain relationship.

phenomenon was represented by fracture parameter $\left(K_{o}\right)$ in the model.

Based on the above assumption, Maekawa and Okamura (1983) proposed the equivalent stress-equivalent strain relationship given in Fig. 2 and Eq. 1.

$$
S=K_{o} C_{o}\left(E-E_{p}\right)
$$

where $S=$ equivalent stress, $E=$ equivalent strain, $C_{o}=$ initial stiffness, which is equal to $2.0, K_{o}$ and $E_{p}=$ fracture parameter and equivalent plastic strain respectively, which are the function of maximum equivalent strain $\left(E_{\text {max }}\right)$ as in the following equation.

$$
\begin{aligned}
& K_{o}=e^{-0.73 E_{\max }\left(1-e^{-1.25 E_{\max }}\right)} \\
& E_{p}=E_{\text {max }}-\frac{20}{7}\left(1-e^{-0.35 E_{\max }}\right)
\end{aligned}
$$

The equivalent stress is a function of mean and deviatoric stresses as defined below:

$$
S=\sqrt{\left(\frac{0.60}{f_{c}^{\prime}} \sigma_{m}\right)^{2}+\left(\frac{1.30}{f_{c}^{\prime}} \tau_{d}\right)^{2}}
$$

where $f_{c}^{\prime}=$ concrete compressive strength, $\sigma_{m}$ and $\tau_{d}=$ mean and deviatoric stresses respectively and are defined as follows:

$$
\begin{gathered}
\sigma_{m}=\frac{\sqrt{2}}{2}\left(\sigma_{1}+\sigma_{2}\right) \\
\tau_{d}=\frac{\sqrt{2}}{2}\left(\sigma_{1}-\sigma_{2}\right)
\end{gathered}
$$

where $\sigma_{1}$ and $\sigma_{2}=$ principal stresses $\left(\sigma_{1} \geq \sigma_{2}\right)$.

The equivalent stress (Eq. 4) is a stress invariant that is normalized by $f_{c}^{\prime}$. The equivalent stress of one $(S=1)$ is in fact the experimentally obtained strength criterion of concrete under biaxial stress. Figure 3 shows the 


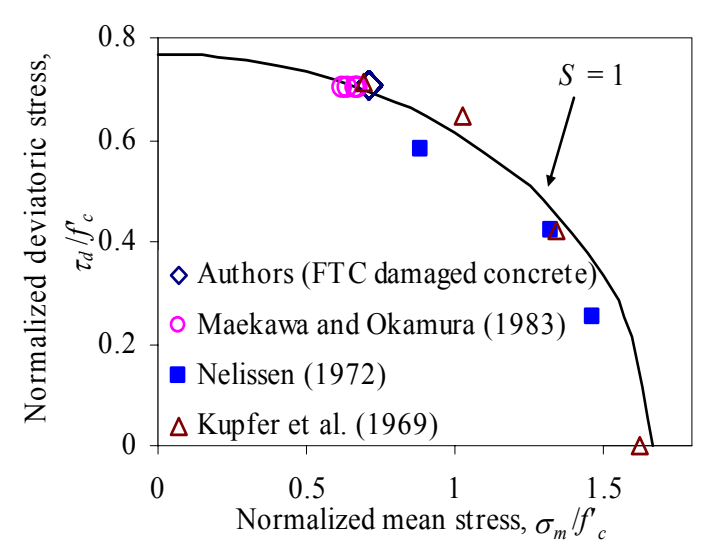

Fig. 3 Failure envelope and equivalent stress with reported data.

acceptable accuracy of Eq. 4 as the failure envelope (for $S=1$ ) for not only concrete without FTC damage (Maekawa and Okamura 1983) but also the concrete with FTC damage tested in this study.

Similar to equivalent stress, the equivalent strain is a function of mean and deviatoric strains as defined in Eq. 6.

$$
E=\sqrt{\left(\frac{0.62}{\varepsilon_{c o}^{\prime}} \varepsilon_{m}\right)^{2}+\left(\frac{0.98}{\varepsilon_{c o}^{\prime}} \gamma_{d}\right)^{2}}
$$

where $\varepsilon_{c o}^{\prime}=$ compressive strain at uni-axial strength, $\varepsilon_{m}$ and $\gamma_{d}=$ mean and deviatoric strains respectively and are defined as follows:

$$
\begin{aligned}
& \varepsilon_{m}=\frac{\sqrt{2}}{2}\left(\varepsilon_{1}+\varepsilon_{2}\right) \\
& \gamma_{d}=\frac{\sqrt{2}}{2}\left(\varepsilon_{1}-\varepsilon_{2}\right)
\end{aligned}
$$

where $\varepsilon_{1}$ and $\varepsilon_{2}=$ principal strains $\left(\varepsilon_{1} \geq \varepsilon_{2}\right)$.

The equivalent strain is a strain invariant normalized by $\varepsilon_{c o}^{\prime}$. The equivalent strain of one $(E=1)$ corresponds to the strain state at the peak stress $(S=1)$. The coefficients, $0.62 / \varepsilon_{c o}^{\prime}$ and $0.98 / \varepsilon_{c o}^{\prime}$ in Eq. 6 were experimentally obtained. As the failure criterion, Eq. 6 (for $E=1$ ) can be applied to both concrete with and without FTC damage as shown in Fig. 4.

Hasan et al. (2002) assumed that FTC causes some of the elements to fracture and lose their ability to carry compression load due to microcracking. The microcracking also causes plastic tensile strain in the constituent elements as shown in Fig. 1(b). Because of the plastic tensile strain occurring in some elements, the unfractured elements with lesser plastic tensile strains cannot effectively carry the compression load. Those ineffective elements, however, can regain their load carrying ability once compressive strain cancels the plastic tensile strain. Accordingly, it is necessary to take an effective factor, $\alpha$, besides the fracture parameter to

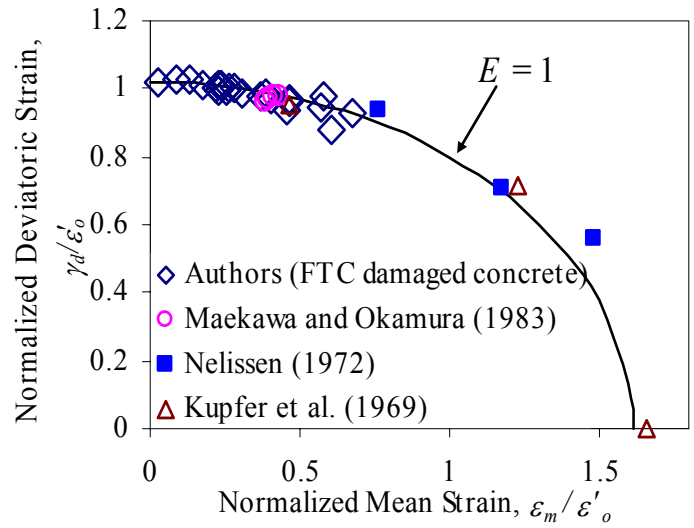

Fig. 4 Failure envelope and equivalent strain with reported data.

represent these phenomena. As a result, the equivalent stress-equivalent strain relationship was modified as shown by Eq. 8 .

$$
S=\alpha K_{o} C_{o}\left(E-E_{p}\right)
$$

where

$$
\alpha=0.34+0.66\left(E_{\max }\right)^{0.32} \leq 1.0
$$

The experimentally observed fact that the stiffness increases slightly as the equivalent strain increases can be predicted by effective factor $\alpha$. Hasan et al. (2002) also reported that the equivalent plastic strain for FTC damaged concrete is higher than that for undamaged concrete and modified Eq. (3) for damaged concrete as follows:

$$
E_{p}=E_{\max }-\frac{21}{13}\left(1-e^{-0.6 E_{\max }}\right)
$$

\section{Experimental program}

Two types of concrete mixtures (series A and B) were prepared. Sixteen concrete cylinder specimens of series A and 17 concrete cylinder specimens of series B were cast. The specimens were $100 \mathrm{~mm}$ in diameter and 200 $\mathrm{mm}$ in height. Normal and early strength Portland cement was used for series A and series B respectively. Series A was air-entrained by using an air-entraining agent. The mix proportion of series A and B for $1 \mathrm{~m}^{3}$ volume is shown in Table 1.

The molds were removed 2 days after casting and the specimens cured in water for 285 days (series A) and 23 days (series B). Four strain gages were mounted on the surface of the specimens (see Fig. 5). Before placing the strain gages, a layer of EP-34B epoxy resin compound was spread on the surface of the specimens at the location of the strain gages and dried for 24 hours. The strain gages were placed by using the same epoxy resin and pressed under a pressure of approximately 30 to 50 
Table 1 Mix proportion of concrete specimens.

\begin{tabular}{|c|c|c|c|c|c|c|c|}
\hline Series & $\begin{array}{c}\mathrm{C} \\
\mathrm{kg}\end{array}$ & $\begin{array}{c}\mathrm{W} \\
\mathrm{kg}\end{array}$ & $\begin{array}{c}\mathrm{G} \\
\mathrm{kg}\end{array}$ & $\begin{array}{c}\mathrm{S} \\
\mathrm{kg}\end{array}$ & $\begin{array}{c}\text { AEW } \\
\mathrm{cc}\end{array}$ & $\begin{array}{c}\text { AEA } \\
\mathrm{cc}\end{array}$ & $\begin{array}{c}\text { AC } \\
\%\end{array}$ \\
\hline $\mathrm{A}$ & 267 & 160 & 1116 & 869 & 668 & 4 & 4.5 \\
\hline $\mathrm{B}$ & 320 & 160 & 1165 & 777 & 0 & 0 & 1.5 \\
\hline
\end{tabular}

$\mathrm{C}=$ cement, $\mathrm{W}=$ water, $\mathrm{G}=$ gravel, $\mathrm{S}=$ sand, $\mathrm{AEW}=$ air-entraining water reducer agent,

$\mathrm{AEA}=$ air-entraining agent, $\mathrm{AC}=$ air content

$\mathrm{kPa}$ for 24 hours and then connected to the wire. The strain gages and uncovered wires were then covered by an epoxy polymer layer and dried for 12 hours. Lastly a layer of coating material was placed on the epoxy polymer layer. On 2 specimens in series A and 2 specimens in series B, 3 thermocouples were placed at different locations to measure the temperature as shown in Fig. 5. Both strain gages and thermocouples were connected to a data logger.

When specimens in series A and B were 300 and 50 days old, respectively, freezing and thawing tests were begun in a climate chamber. The chamber temperature was controlled by 2 temperature sensors located in the chamber and connected to computer PC1 as shown in Fig. 6. The input temperature history for a FTC in this test is shown in Fig. 7. Specimens in series A were exposed to temperature history (a) from the 1 st to 40th cycle and continuously to temperature history (b) up to

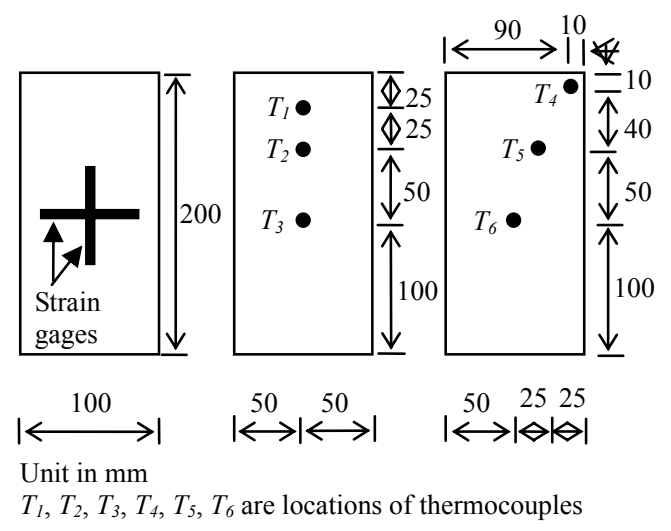

Fig. 5 Location of strain gages and thermocouples.

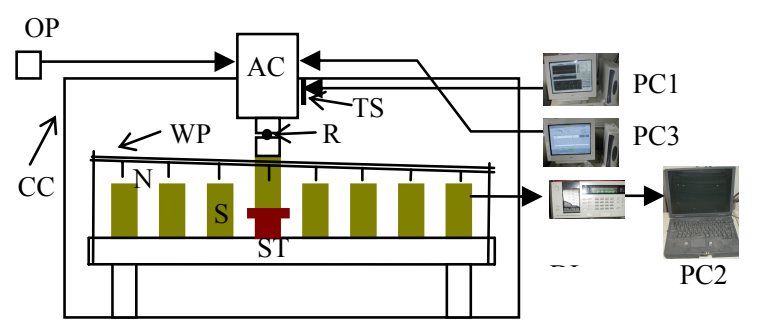

$\mathrm{AC}=$ Actuator, $\mathrm{CC}=$ Climate Chamber; $\mathrm{DL}=$ Data Logger; $\mathrm{N}=$ Nozzle; $\mathrm{OP}=$ Oil Pressure Unit; $\mathrm{PC}=$ Computer; $\mathrm{R}=$ Roller; $\mathrm{S}=$ Specimen, $\mathrm{ST}=$ Stainless Steel Bed; TS=Temperature Sensor; WP=Water Pipe the 188th cycle while specimens in series B were exposed to temperature history (b) during the entire FTC test.

To measure the real chamber temperature, a thermocouple was put in the chamber and connected to the data logger (see Fig. 6). The data logger was connected to computer PC2, so all the temperatures and strains measured in this test were stored in computer PC2. Before the test, the chamber temperature was kept at $20^{\circ} \mathrm{C}$. To maintain the moisture content in the specimens, water was sprayed on the specimens for 15 minutes when the input temperature reached $19^{\circ} \mathrm{C}$ during thawing of each FTC.

After some cycles of freezing and thawing, a compression load was applied on the specimens with displacement control through an actuator. Three specimens were tested for each number of FTC. To measure the plastic strain and unloading stiffness, an unloading-reloading test was performed. The loading rate and history were controlled by computer PC3. During the compression test, the chamber and specimen's temperatures were set to $20^{\circ} \mathrm{C}$. The arrangement of the instruments during the freezing and thawing tests and compression tests is shown in Fig. 6.

The notations used in the rest of this paper correspond to the FTC number - for example, B-100 represents a concrete specimen of series B that was exposed to 100 cycles of freezing and thawing.

\section{Experimental results}

\subsection{Freezing and thawing test results}

The temperature in the climate chamber and the temperatures of the specimens for the first three cycles under the temperature history (b) are shown in Fig 8. It

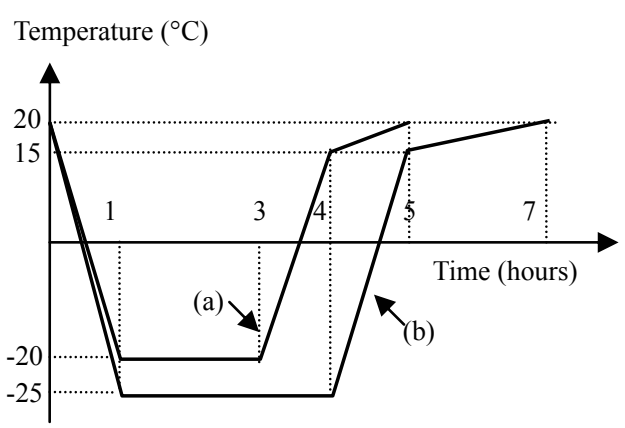

Fig. 7 Input temperature history for FTC.

Fig. 6 Arrangement of instruments. 
can be seen in this figure that the temperature in series A is almost the same as the temperature in series B. To cool the concrete cylinder specimens down to $0^{\circ} \mathrm{C}$ takes approximately 1.5 hours after the chamber temperature reaches $0^{\circ} \mathrm{C}$. During the first cycle, the minimum temperature in the concrete specimens $\left(-20^{\circ} \mathrm{C}\right)$ could not reach the minimum chamber temperature $\left(-25^{\circ} \mathrm{C}\right)$, because when the minimum temperature in the concrete was reached, the chamber temperature started to increase. Thus the cooling temperature in the specimens was affected by the heating process in the chamber. However the minimum temperature in the concrete specimens decreased with the number of FTC and reached the same value as that of the chamber after 10 cycles. The same phenomenon was observed for the maximum temperature. When the maximum temperature in the specimens was reached, the chamber temperature had started to decrease already. The maximum temperature in the specimens was approximately $10^{\circ} \mathrm{C}$, which is lower than the chamber temperature of $20^{\circ} \mathrm{C}$. Temperature variations at different locations inside the specimen were almost the same. It should be mentioned here that the model in this study was developed based

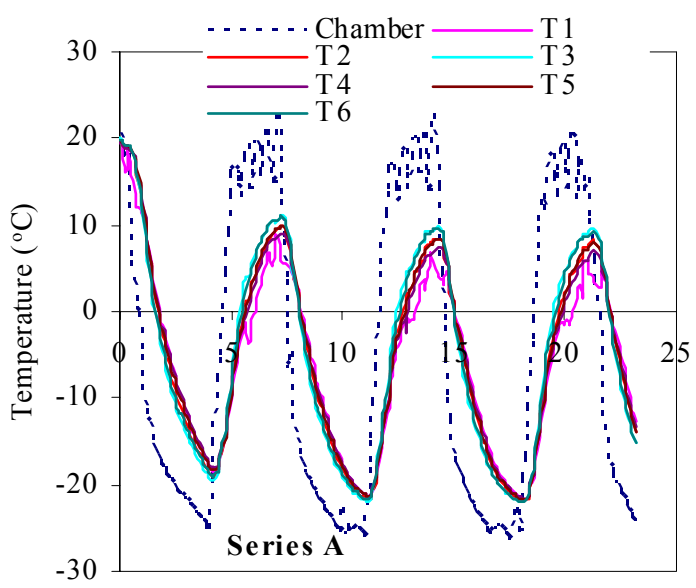

Time (hours)

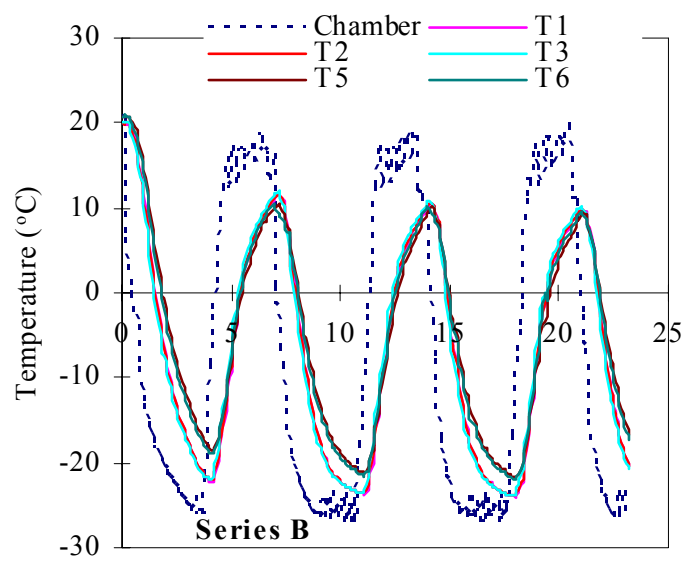

Time (hours)

Fig. 8 Climate chamber and specimen temperatures. on experimental results for specimens in which the temperature variation at different locations is rather uniform.

Figure 9 shows the strains induced during the freezing and thawing test. Since the strains in the lateral direction are almost the same as in the axial direction, in this figure only the strains in the axial direction are shown. At the first cycle of FTC, the pore structures of the concrete are partially filled with water. Once the temperature drops below the freezing point of related pores, the water in large pores freezes. As ice has a lower chemical potential than water, the unfrozen water moves toward the existing ice creating negative hydraulic pressure and shrinkage in the concrete. Because of these phenomena, the strain can be compressive under decreasing temperature. At the lowest temperature, the ice will contract more than the surrounding concrete, creating empty pore spaces that are then filled up by the unfrozen water in smaller pores. The water freezes there because the freezing point of those pores has already been reached. As the temperature rises, the ice expands more than the corresponding pores and creates tension. At the end of the cycle, irreversible tensile strain can be observed. This means that during freezing and thawing some concrete constituent elements have plasticity in tension (see Fig. 1). This plastic tensile strain increases with the number of FTC. After the plastic tensile strain
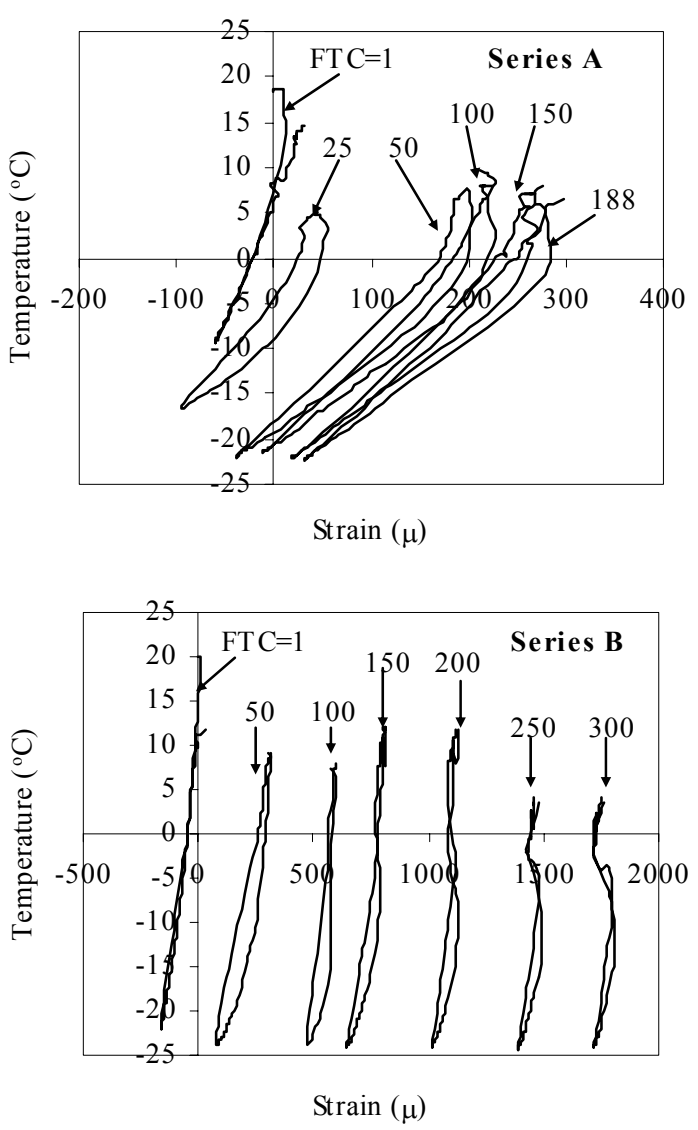

Fig. 9 Strain induced by FTC (Numbers indicating numbers of FTC). 
exceeded $210 \mu$ in both specimens of series A and B, the strain became tensile in the entire temperature range.

When the number of FTC increases, the degree of saturation in pore structures increases by sucking in water near the concrete surface during the thawing process at temperatures above $0^{\circ} \mathrm{C}$. Some of the pore structures are filled fully with water. Below the freezing point of related pores, the volume increase of ice causes tension in the surrounding concrete. If the tensile stress exceeds the tensile strength of concrete, microcracks occur. By continuing FTC, more water can penetrate the existing cracks during thawing, causing higher expansion and more cracks during freezing. This phenomenon can be seen from the fact that the tensile strain for temperature dropping below $0^{\circ} \mathrm{C}$ increases progressively with the number of FTC. When the temperature is between $-10^{\circ} \mathrm{C}$ and $-13^{\circ} \mathrm{C}$ a large amount of water has already frozen. The ice contracts more than the surrounding concrete and the strain decreases until the minimum temperature is reached. When the temperature increases during thawing, the strain again increases as the ice expands more than the surrounding concrete. At temperatures between $-4^{\circ} \mathrm{C}$ and $-1{ }^{\circ} \mathrm{C}$, compressive strains can be seen as an effect of negative hydraulic pressure caused by water redistribution caused by melting of the ice.

Good dispersion of pores in air-entrained concrete

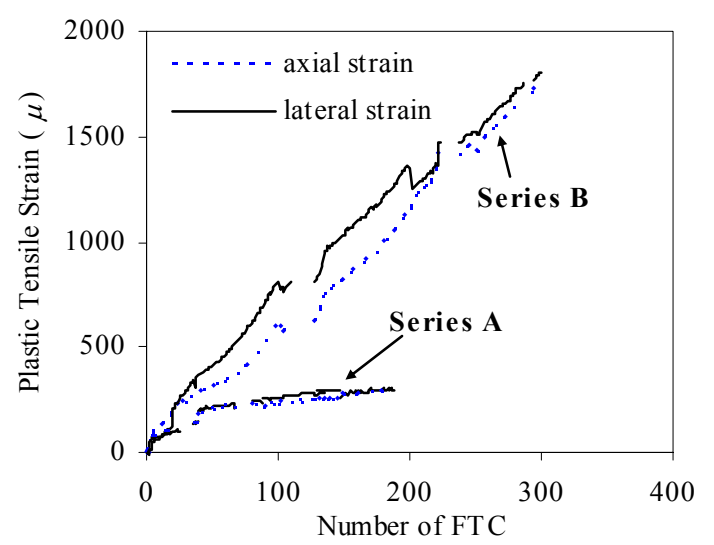

Fig. 10 Plastic tensile strain induced by FTC.

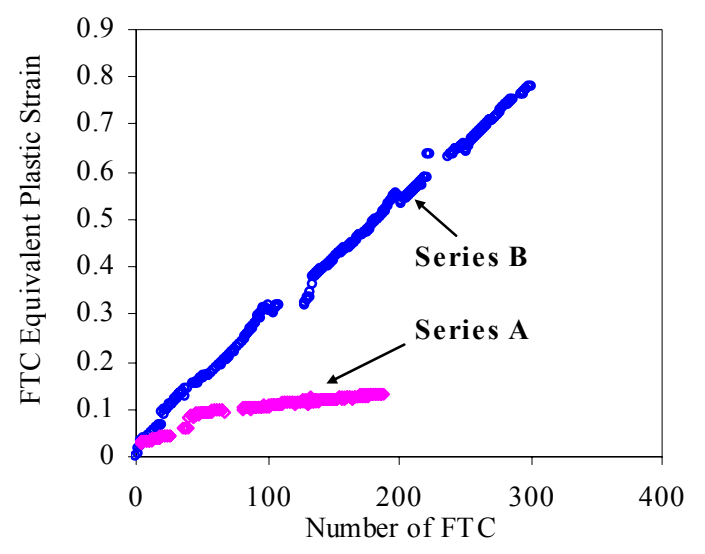

Fig. 11 FTC equivalent plastic strain. (series A) enables easy water flow within the pores, thus preventing cracks from occurring. Sufficient pores for ice expansion are also provided in air-entrained concrete.

In this study, the residual tensile strain occurring after freezing and thawing is denoted as FTC plastic tensile strain. The FTC plastic tensile strain for air-entrained concrete (series A) is observed to be much lower than that for the non air-entrained concrete (series B). These FTC plastic tensile strains are shown in Fig. 10. The test shows that FTC plastic tensile strains in axial and lateral directions are almost same. Using Eqs. 6 and 7 and taking $\varepsilon_{c o}^{\prime}=2000 \mu$, the FTC plastic tensile strains are converted to an equivalent strain and denoted as FTC equivalent plastic strain. The FTC equivalent plastic strain increases as the number of FTC increases, as shown in Fig. 11.

\subsection{Mechanical loading test results}

The mechanical properties for all specimens are summarized in Table 2. The values in Table 2 are the average value of 3 specimens, except for series A-188 for which the listed value is the average of 5 specimens. The relationships between compressive strength, initial modulus of elasticity and the number of FTC are shown in Figs. 12 and 13. The relationships between compressive strength, initial modulus of elasticity and FTC equivalent plastic strain are shown in Figs. 14 and 15.

Table 2 Mechanical properties.

\begin{tabular}{|c|c|c|c|c|}
\hline Series & $E_{p f}$ & $\begin{array}{c}f_{c}^{\prime} \\
(\mathrm{MPa})\end{array}$ & $\begin{array}{c}E_{c o} \\
(\mathrm{GPa})\end{array}$ & $\begin{array}{c}\varepsilon_{c o}^{\prime} \\
(\mu)\end{array}$ \\
\hline A-0 & 0 & 47.8 & 32.8 & 2475 \\
A-88 & 0.099 & 42.7 & 30.7 & 2155 \\
A-148 & 0.121 & 41.3 & 30.5 & 2034 \\
A-188 & 0.131 & 40.9 & 29.4 & 2030 \\
\hline B-0 & 0 & 49.8 & 29.3 & 2355 \\
B-50 & 0.163 & 44.7 & 28.8 & 2139 \\
B-100 & 0.318 & 40.0 & 26.1 & 1848 \\
B-200 & 0.547 & 35.4 & 16.5 & 2131 \\
B-300 & 0.782 & 29.8 & 10.3 & 2370 \\
\hline
\end{tabular}

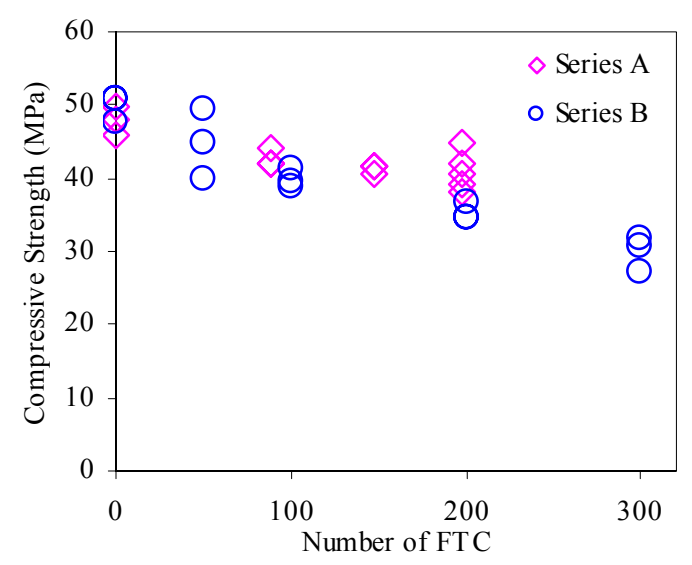

Fig. 12 Relationship between compressive strength and number of FTC. 


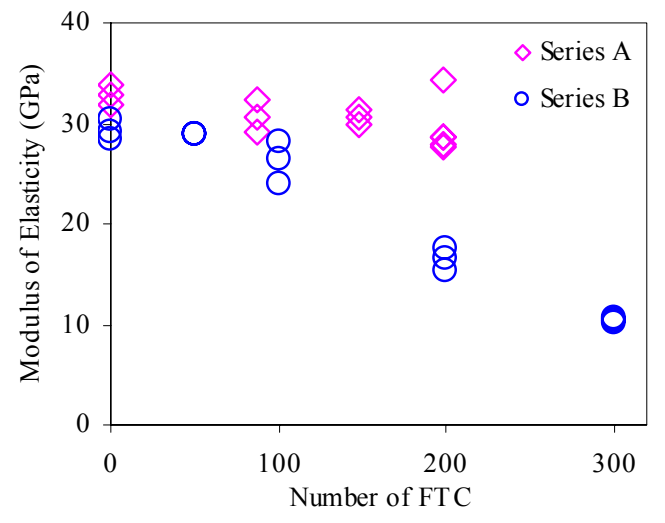

Fig. 13 Relationship between initial modulus of elasticity and number of FTC.

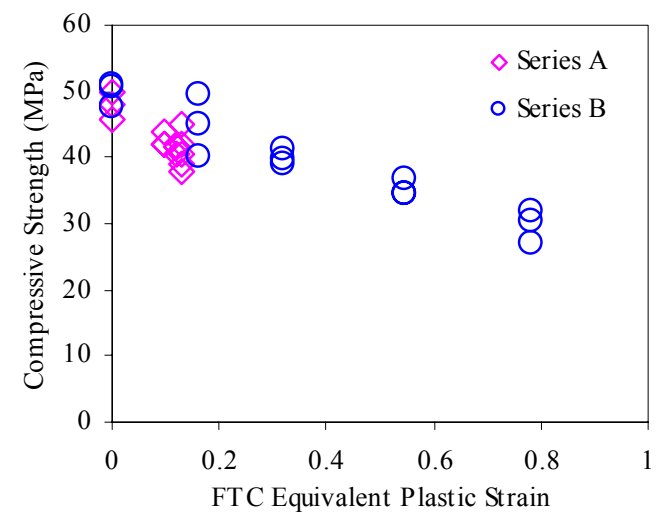

Fig. 14 Relationship between compressive strength and FTC equivalent plastic strain.

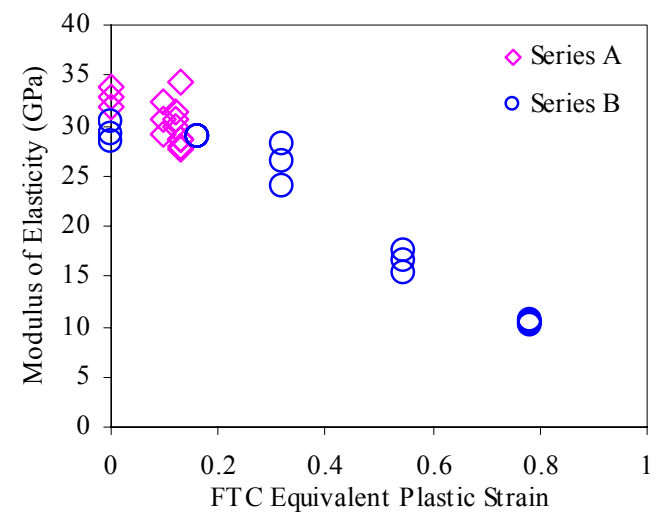

Fig. 15 Relationship between initial modulus of elasticity and FTC equivalent plastic strain.

Internal cracking in the non air-entrained concrete (series B), which means more fracture of the constituent elements during FTC (Fig. 1), causes a very high degradation in initial stiffness after being exposed to a number of FTC. However, since fewer elements fracture during FTC for the air-entrained concrete (series A), small degradation in initial stiffness is observed.

Reloading and unloading processes during the appli-
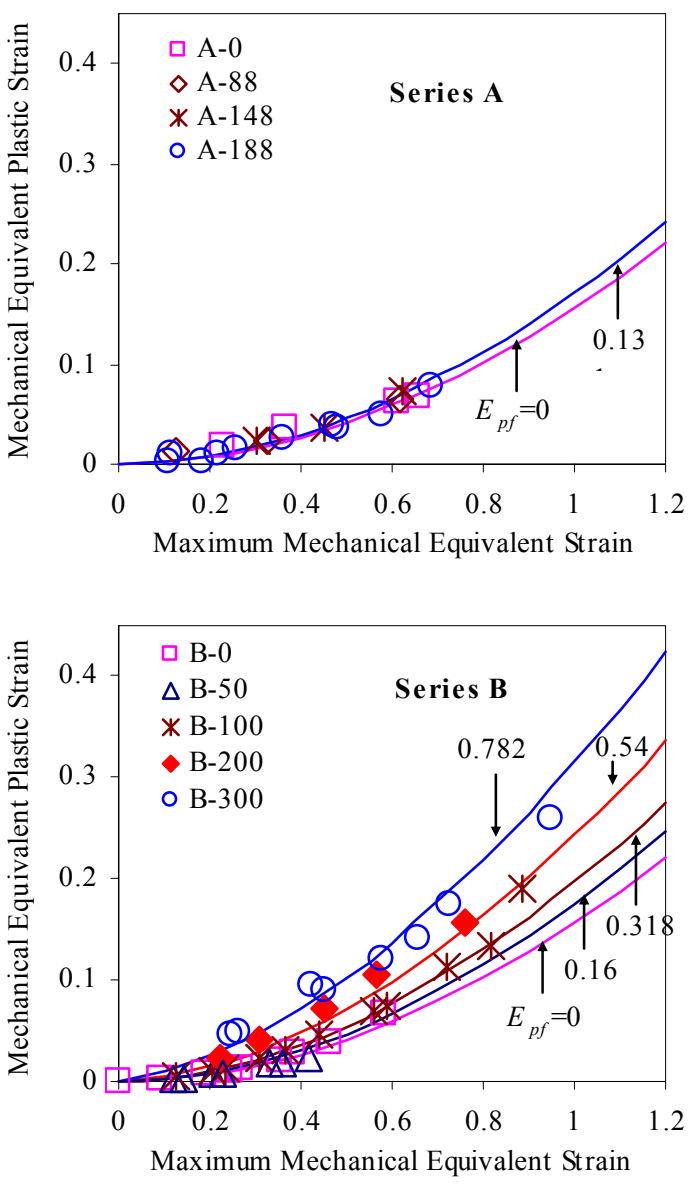

Fig. 16 Mechanical equivalent plastic strain.

cation of compression load at different strain levels enables us to know the elastic and plastic strains in axial and lateral directions at every total strain level. The axial and lateral elastic and plastic strains are converted to the equivalent elastic and equivalent plastic strains using Eqs. 6 and 7. The equivalent plastic strains under the application of mechanical loading for all specimens tested in this study are given in Fig. 16. To distinguish these strains from those occurring under FTC, equivalent strain under the effect of mechanical loading is hereinafter referred to as "mechanical equivalent strain". The mechanical equivalent plastic strain increases with the increase in maximum equivalent strain, which is the experienced maximum mechanical equivalent total strain. It can also be seen that at the same equivalent total strain level, the mechanical equivalent plastic strain for the non air-entrained concrete (series B) is higher than that for the air-entrained concrete (series A).

\section{Formulation of new model}

The stress-strain model developed in this study is based on the same assumption as that of the previous model presented by Hasan et al. (2002) with one difference: the presented model attempts to indicate the fracture induced by FTC. A fracture parameter to consider the 
damage caused by FTC is introduced in addition to the fracture parameter for mechanical loading proposed by Maekawa and Okamura (1983). From here on, the fracture parameter under the effect of FTC is referred to as "FTC fracture parameter," while the fracture parameter under the effect of mechanical loading is referred to as "mechanical fracture parameter." The FTC fracture parameter represents the reduction in initial stiffness resulting from fracture of some elements as concrete is damaged during FTC (see Fig. 1). The FTC fracture parameter is considered to be a function of FTC equivalent plastic strain. By fitting the experimental data shown in Fig. 17, the relationship between FTC fracture parameter and FTC equivalent plastic strain can be given as follows:

$$
\beta=e^{-0.45 E_{p f}\left(1-e^{-30 E_{p f}}\right)}
$$

where $\beta=$ FTC fracture parameter and $E_{p f}=$ FTC equivalent plastic strain.

The mechanical equivalent stress-mechanical equivalent strain relationship then changes from Eq. 8 to Eq. 12 (see Fig. 18). The value of $C_{o}$ in Eq. 12 is still the same as that proposed by Maekawa and Okamura (1983), i.e. $C_{o}=2.0$.

$$
S=\alpha \beta K_{o} C_{o}\left(E-E_{p}\right)
$$

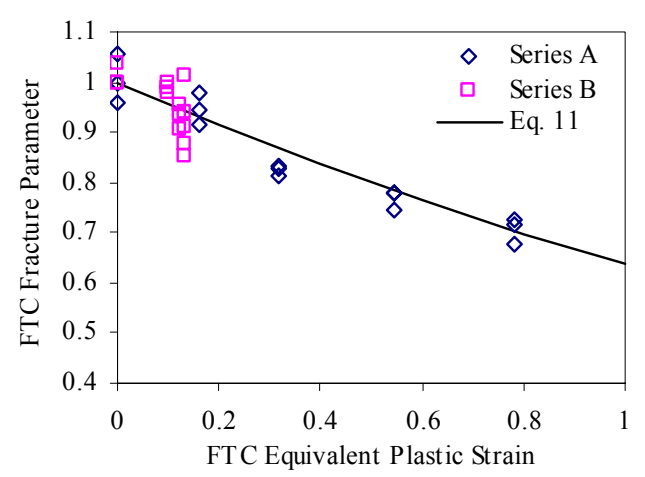

Fig. 17 Formulation of FTC fracture parameter.

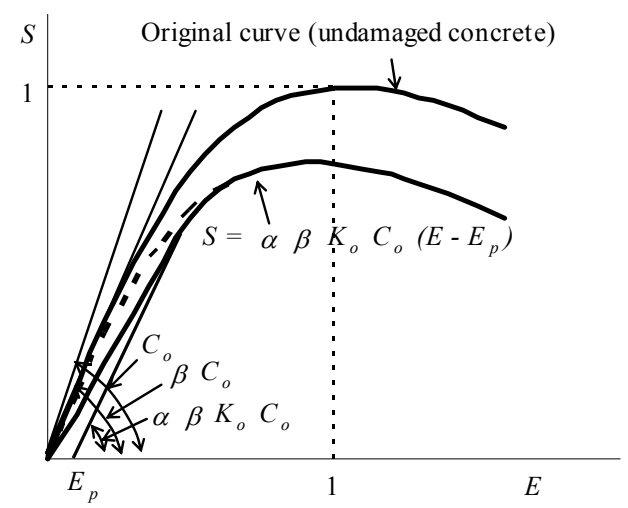

Fig. 18 Mechanical equivalent stress-mechanical equivalent strain relationship in new developed model.
It was newly found that as the plastic tensile strain during FTC increases, effective factor $\alpha$ decreases. For better correlation with the experimental results, the formula for effective factor $\alpha$ is modified as follows:

$$
\begin{aligned}
& \alpha=e^{-1.70 E_{p f}} e^{1.70 E_{p f}^{0.15} E_{\max }^{0.85}} \text { for } E_{\max }<E_{p f} \\
& \alpha=1.0 \text { for }_{\max } \geq E_{p f}
\end{aligned}
$$

It is assumed in Eq. 13 that effective factor $\alpha$ reaches the maximum value $(\alpha=1.0)$ when the maximum mechanical equivalent strain becomes $E_{p f}$ and is constant during an increase in the maximum mechanical equivalent strain that follows.

As the damage in concrete by FTC increases, the mechanical equivalent plastic strain also increases as shown in Fig. 16. This phenomenon occurs because the greater the damage is, the lesser compression the elements carry. These elements reach their plastic point more quickly, resulting in a higher mechanical plastic strain at the same maximum mechanical equivalent strain level. In this model, therefore, the mechanical equivalent plastic strain is also considered to be a function of not only the maximum mechanical equivalent strain but also the FTC equivalent plastic strain, as shown in Eq. 14.

$$
E_{p}=E_{\max }-a\left(1-e^{-b E_{\max }}\right)
$$

where

$$
\begin{aligned}
& a=\frac{20}{7}-2.10 E_{p f}+0.34 E_{p f}^{2} \\
& b=0.35+0.25 E_{p f}+0.18 E_{p f}^{2}
\end{aligned}
$$

The mechanical equivalent plastic strains calculated by Eq. 14 are represented by the solid lines in Fig. 16. A comparison between the calculated mechanical equivalent plastic strains and the measured ones for all the specimens tested in this study is shown in Fig. 19. There is good agreement between the calculated and experi-

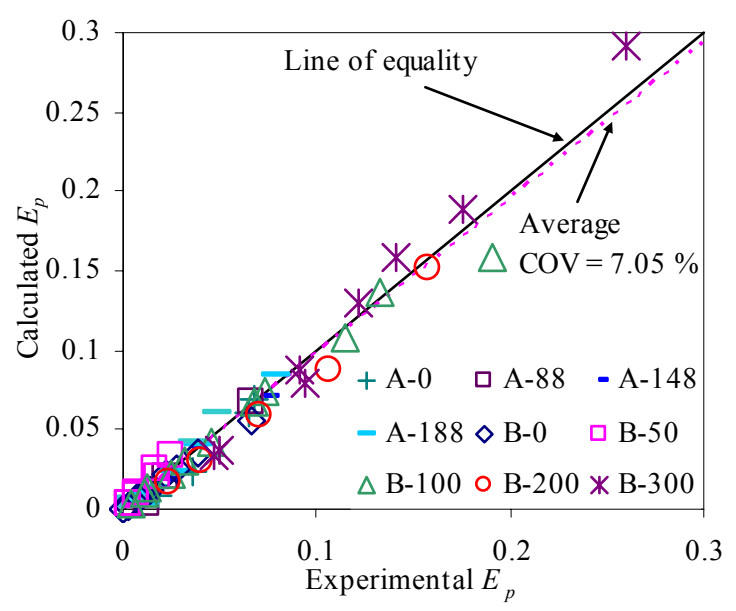

Fig. 19 Comparison between calculated and measured mechanical equivalent plastic strain. 


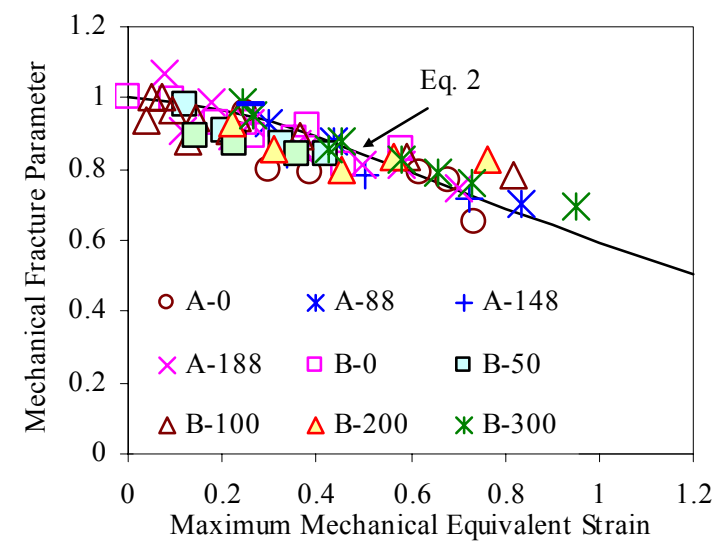

Fig. 20 Mechanical fracture parameter.

mental data for mechanical equivalent plastic strain for both non air-entrained and air-entrained concrete (series $\mathrm{A}$ and $\mathrm{B}$, respectively). The average values of the experimental data are very close to the calculated ones $\left(E_{p, c a l}=0.96 E_{p, \exp }\right)$ with a coefficient of variation of $7.05 \%$

The difference in mechanical fracture parameter $K_{o}$ for concrete with and without damage caused by FTC is practically negligible, as shown in Fig. 20. Therefore, the formula for the mechanical fracture parameter remains unchanged from that in Eq. 2. This means that the effects of FTC on the fracture parameter can be grasped taking into consideration only two factors, $\alpha$ and $\beta$, as shown in Eq. 12.

\section{Correlation between presented model with experiment}

The stress-strain relationships for all specimens tested in this study were analyzed using the model presented in this study. The input parameters for the model were FTC equivalent plastic strain, $E_{p f}$ listed in Table 2, initial stiffness $\left(C_{o}=2.0\right)$, strain at peak stress (since no effect of FTC on this value was observed, the average measured value of $\varepsilon_{c o}^{\prime}$ listed in Table 2 was used, that is $\varepsilon_{c o}^{\prime}=2166 \mu$ ), and compressive strength of the reference concrete A-0 and $\mathrm{N}-0\left(f_{c}^{\prime}=47.8 \mathrm{MPa}\right.$ and 49.8 $\mathrm{MPa}$ for series $\mathrm{A}$ and $\mathrm{B}$, respectively). Parameters $\alpha, \beta$, and $K_{o}$ were calculated using Eq. 13, Eq. 11, and Eq. 2, respectively. The mechanical equivalent plastic strain was calculated using Eqs. 14 and 15. For Poisson's ratio, the equation proposed by Hasan et al. (2002) was adopted. A comparison between the calculated

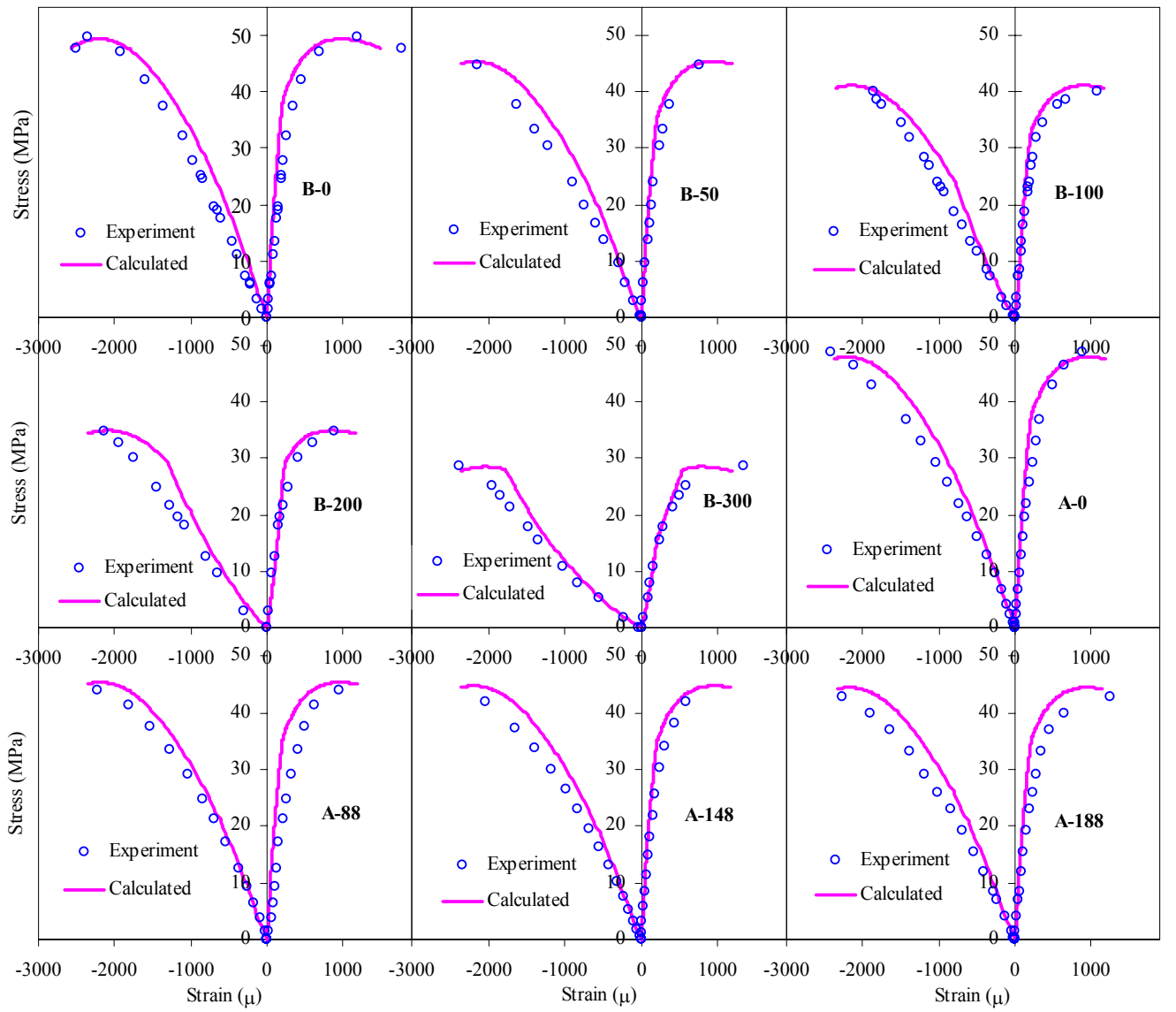

Fig. 21 Comparison between calculated and experimental stress-strain curves. 


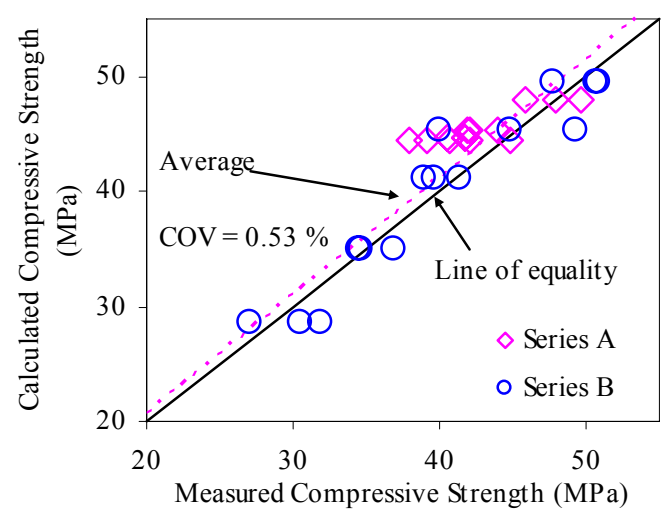

Fig. 22 Comparison between calculated and experiment maximum compressive stresses.

stress-strain curves and the experimental ones for all specimens tested in this study is shown in Fig. 21. The good correlation between the calculated and experimental data confirms the applicability of the model to predict the observed experimental trends for both series $\mathrm{A}$ and $\mathrm{B}$.

The maximum compressive stresses obtained by calculation using the presented model are compared with the experimental ones in Fig. 22. The average values of the experimental data are very close to the calculated ones $\left(\bar{f}_{c, \exp }^{\prime} / \bar{f}_{c, c a l}^{\prime}=0.97\right)$ with a $0.53 \%$ variation coefficient. A good agreement between the experimental and calculated data can thus be seen.

\section{Conclusions}

A stress-strain model relating to stiffness degradation of concrete under the effect of freezing and thawing cycles (FTC) was described. The model was developed based on the authors' previous model with the concept of plasticity and fracture in concrete under the effect of mechanical loading (Hasan et al. 2002). For the stress-strain model under the effect of freezing and thawing, the FTC fracture parameter was introduced besides the fracture parameter for mechanical loading to express degradation in initial stiffness caused by microcracking during freezing and thawing exposure. The FTC fracture parameter in this model was empirically given as a function of remaining expansion of concrete caused by freezing and thawing (Eq. 11). This expansion was denoted by the FTC equivalent plastic strain. The plastic strain under application of mechanical load for concrete damaged by FTC was also formulated considering the effect of expansion caused by freezing and thawing as well as the effect of the application of mechanical load (Eq. 14).

Using this model, the stress-strain relationships for both air-entrained and non air-entrained concrete in the axial and lateral directions under different degrees of FTC damage were obtained. The results showed good correlation with the experimental data. This indicates that FTC equivalent plastic strain can be a good parameter to describe the mechanical response of concrete damaged by FTC.

The presented model has the merit of requiring only the plastic tensile strain induced by FTC in addition to the compressive strength and strain at the peak stress of the original undamaged concrete. The next task will be to predict this plastic tensile strain under a given temperature history and to expand the present model for more general combined effects of FTC and mechanical loading.

\section{Acknowledgements}

The authors would like to express their gratitude to Prof. Yoshio Kakuta of Hokkaido University for his valuable comments regarding this study and to Mr. Tsutomu Kimura and Mr. Kohei Nagai of Hokkaido University for their assistance in the experimental work carried out in this study.

\section{References}

Fagerlund, G. (2002). "Mechanical damage and fatigue effects associated with freeze-thaw of materials." M. J. Setzer, R. Auberg and H. J. Keck, Eds. Proc. 2nd International RILEM Workshop on Frost Resistant of Concrete, Essen 18-19 April 2002. Cachan Cedex: RILEM Publications S.A.R.L., 197-204.

Hasan, M., Ueda, T., Sato, Y. and Nagai. K. (2001). "Experimental study on tension and compression behavior of plain concrete after freezing and thawing exposure." Proc. of Hokkaido Chapter of JSCE, No. 57, 808-811.

Hasan, M., Nagai, K., Sato, Y. and Ueda, T. (2002). "Stress-strain behavior in tension and compression of concrete damaged by freezing and thawing cycles." M. J. Setzer, R. Auberg and H. J. Keck, Eds. Proc. 2nd International RILEM Workshop on Frost Resistant of Concrete, Essen 18-19 April 2002. Cachan Cedex: RILEM Publications S.A.R.L., 197-204.

Kasparek, S. and Setzer, M. J. (2002). "Analysis of heat flux and moisture transport in concrete during freezing and thawing." M. J. Setzer, R. Auberg and H. J. Keck, Eds. Proc. 2nd International RILEM Workshop on Frost Resistant of Concrete, Essen 18-19 April 2002. Cachan Cedex: RILEM Publications S.A.R.L., 197-204.

Kaufmann, J. P. (2002). "A qualitative sequential frost deicing salt damage model based on experimental data." M. J. Setzer, R. Auberg and H. J. Keck, Eds. Proc. 2nd International RILEM Workshop on Frost Resistant of Concrete, Essen 18-19 April 2002. Cachan Cedex: RILEM Publications S.A.R.L., 197-204.

Kupfer, H., Hilsdorf, H. K. and Rusch, H. (1969). "Behavior of concrete under biaxial stresses." Journal of ACI, 66 (8), 656-666.

Maekawa, K. and Okamura, H. (1983). "The 
deformational behavior and constitutive equation of concrete using the elasto-plastic and fracture model." Journal of the Faculty of Engineering, the University of Tokyo (B), XXXVII (2), 253-328.

Nelissen, L. J. M. (1972). "Biaxial testing of normal concrete.", HERON, 18 (1), Delft.

Panchenko, A. I. (1997). "Frost failure and rapid test method of concrete frost resistant." M. J. Setzer and R. Auberg, Eds. Proc. 1st International RILEM Workshop on Frost Resistant of Concrete, Essen 22-23 September 1997. Cachan Cedex: RILEM Publications S.A.R.L., 299-306.

Penttala, V. (2002). "From freezing and thawing pore water pressures to concrete stresses." M. J. Setzer, R. Auberg and H. J. Keck, Eds. Proc. 2nd International RILEM Workshop on Frost Resistant of Concrete, Essen 18-19 April 2002. Cachan Cedex: RILEM Publications S.A.R.L., 197-204.

Penttala, V. and Al-Neshawy, F. (1999). "Ice formation and pore water redistribution during 2-cycle freezing and thawing of concrete mortars." J. Janssen, M. J. Setzer and M.B. Snyder, Eds. International RILEM Workshop on Frost Resistance of Concrete, Minneapolis 28-30 June 1999. Cachan Cedex: RILEM Publications S.A.R.L., 115-126.

Penttala, V. and Al-Neshawy, F. (2002). "Stress and strain state of concrete during freezing and thawing cycles." Cement and Concrete Research, 32, 1407-1420.

\section{Appendix: Notation}

$a, b$ : constants for the effect of freezing and thawing damage on mechanical equivalent plastic strain $C_{o}$ : initial stiffness for equivalent stress-equivalent strain relationship

$E$ : mechanical equivalent strain

$E_{c o}$ : initial modulus of elasticity

$E_{p}$ : mechanical equivalent plastic strain

$E_{p f}:$ FTC equivalent plastic strain

$E_{\text {max }}$ : maximum mechanical equivalent strain

$f_{c}^{\prime}$ : compressive strength

$K_{o}$ : mechanical fracture parameter

$S$ : mechanical equivalent stress

$\alpha$ : effective parameter

$\beta$ : FTC fracture parameter

$\varepsilon_{1}, \varepsilon_{2}$ : principal strains

$\varepsilon_{c o}^{\prime}$ : strain at maximum compressive stress

$\varepsilon_{m}:$ mean strain

$\gamma_{d}$ : deviatoric strain

$\sigma_{1}, \sigma_{2}:$ principal stresses

$\sigma_{m}$ : mean stress

$\tau_{d}:$ deviatoric stress 